\title{
Epidemiology of antenatal depression in Africa: a systematic review and meta- analysis
}

Abel Fekadu Dadi ${ }^{1,2}$, Haileab Fekadu Wolde ${ }^{1 *}$, Adhanom Gebreegziabher Baraki ${ }^{1}$ and Temesgen Yihunie Akalu $^{1}$

\begin{abstract}
Background: Antenatal depression is a serious problem worldwide that has devastating consequences not only for the mother but also for the child and family. The pooled evidence regarding the prevalence and associated factors of antenatal depression is rare in Africa. Hence this review aimed to investigate the prevalence and associated factors of antenatal depression in Africa.

Methods: We searched CINHAL, MEDLINE, PsycINFO, Psychiatry online, PubMed, SCOPES, and Emcare databases for English written observational studies conducted in Africa from 2007 to 2018.Quality of studies was assessed using the Newcastle Ottawa Scale (NOS), and studies with good quality were included in the final review. Heterogeneity across studies was assessed using the $P^{2}$ and Higgins test. Publication bias was checked using Funnel plot symmetry, and Egger's regression test and adjustment was made by using Duval and Tweedie's Trim and Fill analysis. A random effect Meta-analysis was employed to determine the pooled estimates with $95 \%$ confidence interval (CI). Stata 14 was used for analysis. The review protocol has been registered in PROSPERO number CRD42018106717.
\end{abstract}

Result: Of the 175 studies identified, 28 studies with an overall sample size of 17,938 were included. According to the random effect model following trim and fill analysis, the pooled prevalence of antenatal depression in Africa was 26.3\% (95\%Cl: 22.2, 30.4\%). Economic difficulties [POR $\left.=1.87 ; 95 \% \mathrm{Cl}: 1.25,2.78, \mathrm{I}^{2}=88.1 \%\right]$, unfavorable marital condition $\left[\mathrm{POR}=4.17 ; 95 \% \mathrm{Cl}: 1.75,9.94, P^{2}=81.2 \%\right]$, poor support from relatives $\left[\mathrm{POR}=1.36 ; 95 \% \mathrm{Cl}: 1.18,1.56, P^{2}=\right.$ 78.0\%], bad obstetric history $\left.[\mathrm{POR}=2.30 ; 95 \% \mathrm{Cl}: 1.81,2.92), P^{2}=81.7 \%\right]$, and history of mental health problem $[\mathrm{POR}=$ 2.97; 95\% Cl:1.74, 5.06, $P=92.0 \%]$ were the factors associated with antenatal depression.

Conclusion: The prevalence of antenatal depression is high in Africa, which showed that one in four pregnant women had depression. Pregnant mothers who had economic difficulties, bad obstetric history, poor support from relatives, previous mental health problems, and unfavorable marital conditions were at higher risk of antenatal depression. Therefore these factors should be considered while designing mental health care services for pregnant mothers.

Keywords: Antenatal depression, Associated factors, Systematic review, Meta-analysis, Africa

\footnotetext{
* Correspondence: haileabfekadu@gmail.com

'University of Gondar, College of Medicine and Health Sciences, Institute of

Public Health, Department of Epidemiology and Biostatistics, Gondar,

Ethiopia

Full list of author information is available at the end of the article
}

(C) The Author(s). 2020 Open Access This article is licensed under a Creative Commons Attribution 4.0 International License, which permits use, sharing, adaptation, distribution and reproduction in any medium or format, as long as you give appropriate credit to the original author(s) and the source, provide a link to the Creative Commons licence, and indicate if changes were made. The images or other third party material in this article are included in the article's Creative Commons licence, unless indicated otherwise in a credit line to the material. If material is not included in the article's Creative Commons licence and your intended use is not permitted by statutory regulation or exceeds the permitted use, you will need to obtain permission directly from the copyright holder. To view a copy of this licence, visit http://creativecommons.org/licenses/by/4.0/ The Creative Commons Public Domain Dedication waiver (http://creativecommons.org/publicdomain/zero/1.0/) applies to the data made available in this article, unless otherwise stated in a credit line to the data. 


\section{Background}

Depression is one of the types of mood disorders characterized by markedly decreased interest or pleasure in almost all activities, significant weight loss or gain, disturbed sleep, feeling of fatigue, loss of appetite, feeling of hopelessness, reduced self-esteem and confidence, diminished ability to think or concentrate, and recurrent thoughts of death $[1,2]$. According to the World Health Organization (WHO) 2017 estimate, 322 million people are living with depression, and29.9 million (9\%) of these are living in Africa. Depressive disorders are ranked among the top five contributors to the global disease burden [3]. The prevalence of depression increased by 18.4\% between 2005 and 2015 worldwide [4].

Antenatal depression is a non-psychotic depressive episode ranging from mild to severe symptoms that occur while the woman is pregnant $[5,6]$. Women are known to be at higher risk of mental disorders like depression than males [7]. The mental health of women of reproductive age is becoming a significant public health problem both in developing and developed countries, and depression is the most prevalent mental disorder during pregnancy $[8$, 9]. A systematic review and meta-analysis conducted in developed countries showed the prevalence of depression to be $7.4,12.8$, and $12 \%$ at the first, second, and third trimesters of pregnancy, respectively [10]. Another metaanalysis conducted worldwide also reported the prevalence of antenatal depression that ranges from 0.5 to $51 \%$ [11]. Moreover, a similar study from low-and middleincome countries also showed a mean weighted prevalence of common mental disorders during pregnancy to be $15.6 \%$ [12]. The magnitude of antenatal depression varies across different countries in Africa, and studies showed the prevalence to be between 8.3 and $78.2 \%[8,13-18]$.

Depressive disorders during pregnancy may have devastating consequences not only for the mother but also for the child and family [19]. Antenatal depression is identified to be a risk factor for adverse obstetric and birth outcomes like fetal growth retardation, low Apgar score, preterm birth, low birth weight, and stillbirth [13, 20-23]. Antenatal depression is also associated with increased smoking, alcohol consumption, and unhealthy behaviors [24]. These factors, together with depression, may predispose the mothers to obstetric complications [19] such as preterm labor [25], preeclampsia, abruption placenta [26, 27]. Furthermore, depression during pregnancy is also associated with postnatal depression [28], which negatively affects child development, motherinfant interaction, and the family at large [9].

Compared with women in developed countries, women in developing countries are more exposed to the risk factors for the development of antenatal depression, such as; younger age of mothers [18], low level of education, exposure to domestic violence [8] or relationship conflicts [18], history of obstetric complications, history of depression [15, 29,30], unplanned pregnancy, lack of social support [27, 31], and low economic status [30].

Despite variations in the magnitude and associated factors of antenatal depression across different countries of Africa, pooling the available evidence and reporting the extent of the problem in a more precise way might help policymakers to prioritize the problem more than ever. Therefore, the objective of the current review is to assess the epidemiology of antenatal depression in Africa.

\section{Method}

\section{Search strategy and selection criteria}

The study conforms to the Preferred Reporting Items for Systematic Reviews and Meta-Analysis (PRISMA) guidelines [32]. The reviewed articles were sourced from the following databases: MEDLINE (via Ovid), PsycINFO, CINAHL (EBSCO), Psychiatry Online, Emcare, PubMed, Scopus. Besides, google scholar, snowballing, and retrieving references from a list of eligible studies were employed. A search strategy was developed for each database by using a combination of free texts and controlled vocabularies (i.e., Mesh terms).

Example of the search strategy for PubMed:

((Prenatal depression) OR antenatal depression) OR "depression during pregnancy" Filters: Observational Study; Publication date from 2007/01/01 to 2018/ 08/02; Humans; English; Africa

We included all observational (cross-sectional, casecontrol, prospective, and retrospective cohort) studies conducted in Africa, which conducted from 2007 up to 2018 and included antenatal depression and associated factors as a primary outcome. Additionally, studies included must have used a validated tool to screen depression, and they must be available in the English language. Studies that were reviewed, studies with a poor quality based on NOS [33], and studies that were conducted on high-risk population groups were excluded from the review.

Articles were independently screened in two stages: firstly, the titles and abstracts were screened, and secondly, the full-text articles that met the eligibility criteria mentioned above were retrieved and screened further for possible inclusion by two reviewers (AFD and HFW). Where there was disagreement between the two reviewers, further discussion was made until a consensus reached.

\section{Data extraction}

The data extraction sheet was prepared to collect information on the name of the author, year of publication, country, study setting(i.e., population-based versus 
institution-based), study design, sample size, time of screening for the depression, the tool used to screen depression, and the prevalence estimates of antenatal depression. Data were extracted by two reviewers (AFD and AGB) from publications, and HFW crosschecked for accuracy.

\section{Data quality and risk of bias assessment}

The quality of evidence and risk of bias for studies (casecontrol and cohort) was assessed using the NewcastleOttawa Scale (NOS). Crossectional studies were also assessed using an adapted version of NOS. The criteria include 3 categories with a maximum score of 9 points. The first is the "selection" category, which accounts for a maximum of 4 points, the second is the "comparability" category, which accounts for a maximum of 2 points, and the third is "outcome," which accounts for a maximum of 3 points. Based on the composite score from these three categories, the studies were classified as good quality if the score is $\geq 7$ points, fair quality 2 to 6 points, and poor quality $\leq 1$ point [33]. Only studies with good quality were included in this review.

\section{Data analysis}

Meta-analysis was conducted to synthesize the pooled prevalence of antenatal depression and the odds ratio of the associated factors using the random effect model. To determine the extent of variation between the studies, we did a heterogeneity test using the Higgins method, which was quantified by $I^{2}$ values [34]. Publication bias was assessed by using the symmetry of the Funnel plot and statistically by Egger's regression test. Duval and Tweedie's Trim and fill analysis was done to correct for publication bias [34, 35]. Sub-group analysis for the pooled prevalence was done, and sensitivity analysis was also carried out to detect any effect of outlier study that significantly affected the pooled estimate. Odds ratio

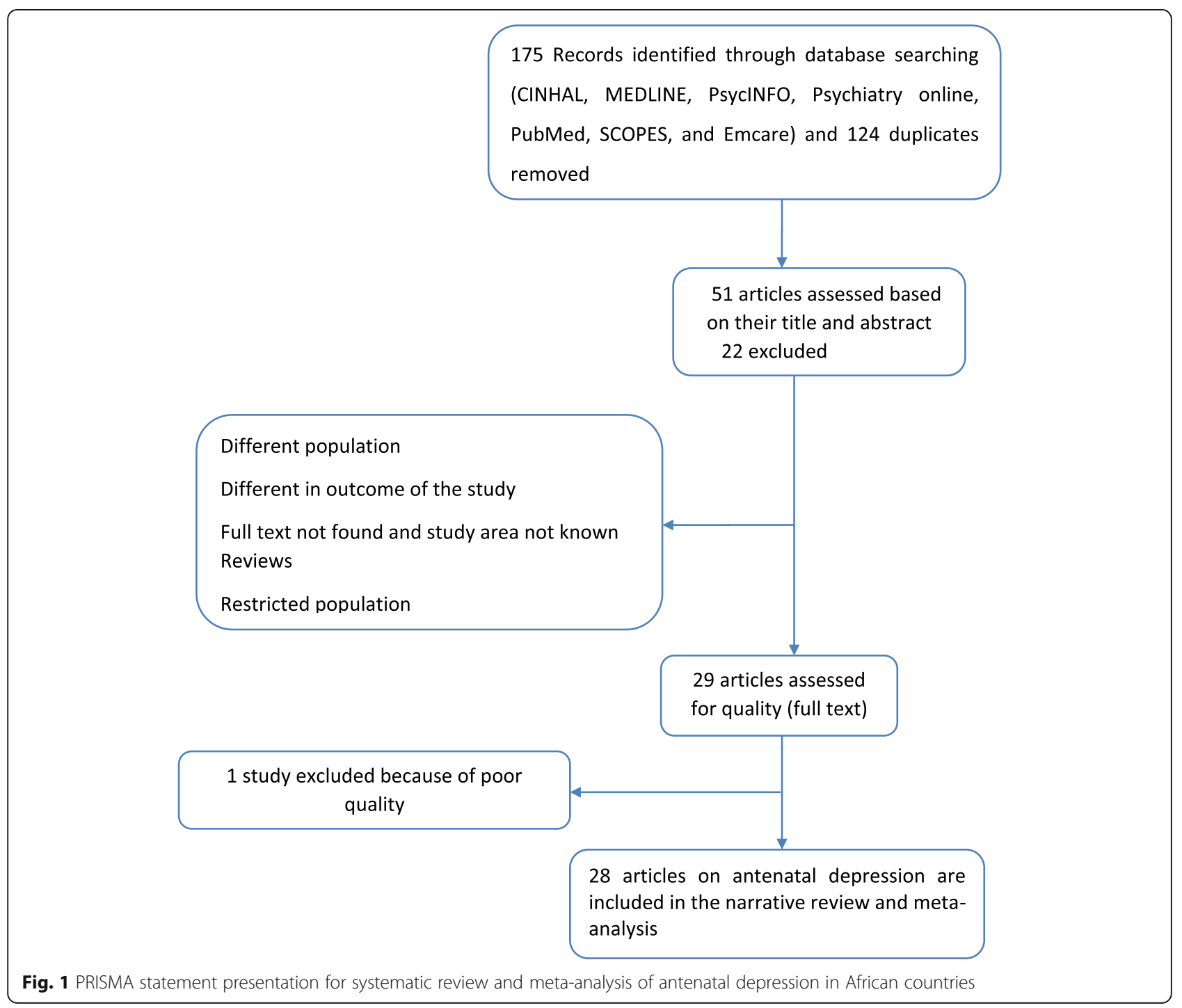


Table 1 Summary of studies conducted on antenatal depression in African countries ( $N=64,2007-2018)$

\begin{tabular}{|c|c|c|c|c|c|c|c|c|}
\hline Author, P. year & Country & $\begin{array}{l}\text { Study } \\
\text { setting }\end{array}$ & $\begin{array}{l}\text { Study } \\
\text { design }\end{array}$ & $\begin{array}{l}\text { Sample } \\
\text { size }\end{array}$ & $\begin{array}{l}\text { Time of } \\
\text { screening }\end{array}$ & $\begin{array}{l}\text { The tool used for screening } \\
\text { depression }\end{array}$ & Prevalence & $\begin{array}{l}\text { Final score of NOS } \\
\text { assessment }\end{array}$ \\
\hline $\begin{array}{l}\text { Adewuya, A. O. et al. } \\
2007\end{array}$ & Nigeria & $\mathrm{HI}$ & $\begin{array}{l}\text { cross- } \\
\text { sectional }\end{array}$ & 180 & Third trim & DSM-IV & $8.30 \%$ & 7 \\
\hline Esimai, O. et al. 2008 & Nigeria & $\mathrm{HI}$ & $\begin{array}{l}\text { cross } \\
\text { sectional }\end{array}$ & 195 & All trim & HADS (not found) & $10.80 \%$ & 7 \\
\hline Kaaya SF et al. 2010 & Tanzania & $\mathrm{HI}$ & $\begin{array}{l}\text { cross } \\
\text { sectional }\end{array}$ & 560 & Second trim & $\mathrm{HSC} \geq 1.06$ & $39.50 \%$ & 7 \\
\hline Hartley M et al., 2011 & $\begin{array}{l}\text { South } \\
\text { Africa }\end{array}$ & Community & $\begin{array}{l}\text { cross- } \\
\text { sectional }\end{array}$ & 1062 & All trim & EPDS $\geq 14$ & $39 \%$ & 8 \\
\hline Rochat TG et al., 2011 & $\begin{array}{l}\text { South } \\
\text { Africa }\end{array}$ & $\mathrm{HI}$ & $\begin{array}{l}\text { cross- } \\
\text { sectional }\end{array}$ & 109 & Second trim & DSM-IV & $47 \%$ & 7 \\
\hline $\begin{array}{l}\text { Manikkam L et al., } \\
2012\end{array}$ & $\begin{array}{l}\text { South } \\
\text { Africa }\end{array}$ & $\mathrm{HI}$ & $\begin{array}{l}\text { cross- } \\
\text { sectional }\end{array}$ & 387 & Third trim & EPDS $\geq 13$ & $38.50 \%$ & 7 \\
\hline Stewart RS et al., 2014 & Malawi & $\mathrm{HI}$ & $\begin{array}{l}\text { cross- } \\
\text { sectional }\end{array}$ & 583 & Second trim & $S R Q \geq 8$ & $21.10 \%$ & 7 \\
\hline $\begin{array}{l}\text { Weobong B et al. } \\
2014\end{array}$ & Ghana & Community & cohort & 2086 & First trim & $\mathrm{PHQ} \geq 10$ & $9.90 \%$ & 8 \\
\hline Abdelhai R et al. 2015 & Egypt & $\mathrm{HI}$ & $\begin{array}{l}\text { cross- } \\
\text { sectional }\end{array}$ & 376 & All trim & HADS > 10 & $10.40 \%$ & 8 \\
\hline Bindt C et al. 2013 & Ghana & $\mathrm{HI}$ & cohort & 719 & Third trim & $\mathrm{PHQ} \geq 10$ & $28.90 \%$ & 8 \\
\hline Mahenge B et al. 2015 & Tanzania & $\mathrm{HI}$ & $\begin{array}{l}\text { cross } \\
\text { sectional }\end{array}$ & 1180 & All trim & $\mathrm{HSC} \geq 1.06$ & $78.20 \%$ & 7 \\
\hline $\begin{array}{l}\text { RwakaremaM et a; } \\
2015\end{array}$ & Tanzania & $\mathrm{HI}$ & $\begin{array}{l}\text { cross- } \\
\text { sectional }\end{array}$ & 397 & All trim & $E P D S \geq 13$ & $33.80 \%$ & 8 \\
\hline $\begin{array}{l}\text { Heyningen T et al. } \\
2015\end{array}$ & $\begin{array}{l}\text { South } \\
\text { Africa }\end{array}$ & $\mathrm{HI}$ & $\begin{array}{l}\text { cross- } \\
\text { sectional }\end{array}$ & 376 & All trim & MINI & $22 \%$ & 7 \\
\hline Malqvist M et al. 2016 & Swaziland & Community & $\begin{array}{l}\text { cross- } \\
\text { sectional }\end{array}$ & 1038 & Third trim & EPDS $\geq 13$ & $22.70 \%$ & 7 \\
\hline $\begin{array}{l}\text { Thompson O et al. } \\
2016\end{array}$ & Nigeria & $\mathrm{HI}$ & $\begin{array}{l}\text { cross- } \\
\text { sectional }\end{array}$ & 314 & All trim & EPDS $>11$ & $24.50 \%$ & 8 \\
\hline Dibaba Y et al. 2013 & Ethiopia & Community & $\begin{array}{l}\text { cross- } \\
\text { sectional }\end{array}$ & 627 & Third trim & EPDS $\geq 13$ & $19.90 \%$ & 8 \\
\hline Gemta A et al. 2013 & Ethiopia & $\mathrm{HI}$ & $\begin{array}{l}\text { cross- } \\
\text { sectional }\end{array}$ & 660 & All trim & EPDS (not found) & $25.60 \%$ & 8 \\
\hline Biratu A et al. 2015 & Ethiopia & $\mathrm{HI}$ & $\begin{array}{l}\text { cross- } \\
\text { sectional }\end{array}$ & 393 & All trim & EPDS $\geq 13$ & $24.94 \%$ & 8 \\
\hline Ayele TA et al. 2016 & Ethiopia & $\mathrm{HI}$ & $\begin{array}{l}\text { cross- } \\
\text { sectional }\end{array}$ & 388 & All trim & $\mathrm{BDI} \geq 16$ & $23.00 \%$ & 8 \\
\hline $\begin{array}{l}\text { Bisetegn TA et al. } \\
2016\end{array}$ & Ethiopia & Community & $\begin{array}{l}\text { cross- } \\
\text { sectional }\end{array}$ & 527 & All trim & EPDS $\geq 12$ & $11.80 \%$ & 8 \\
\hline Bitew T et al. 2016 & Ethiopia & Community & $\begin{array}{l}\text { cross- } \\
\text { sectional }\end{array}$ & 1311 & Second trim & $\mathrm{PHQ} \geq 5$ & $29.50 \%$ & 8 \\
\hline Mossie Tb et al. 2017 & Ethiopia & $\mathrm{HI}$ & $\begin{array}{l}\text { cross- } \\
\text { sectional }\end{array}$ & 196 & All trim & $\mathrm{BDI} \geq 14$ & $31.10 \%$ & 8 \\
\hline Sahile MA et al. 2017 & Ethiopia & $\mathrm{HI}$ & $\begin{array}{l}\text { cross- } \\
\text { sectional }\end{array}$ & 231 & Third trim & $\mathrm{BDI} \geq 21$ & $31.20 \%$ & 8 \\
\hline Guo N et al. 2013 & Ghana & $\mathrm{HI}$ & cohort & 654 & Third trim & $P H Q \geq 10$ & $26.30 \%$ & 7 \\
\hline Guo N et al. 2013 & $\begin{array}{l}\text { Cote } \\
\text { devour }\end{array}$ & $\mathrm{HI}$ & cohort & 654 & Third trim & $\mathrm{PHQ} \geq 10$ & $28.30 \%$ & 7 \\
\hline Bitew T et al. 2017 & Ethiopia & Community & cohort & 1240 & 2nd \& third & $\mathrm{PHQ} \geq 5$ & $28.70 \%$ & 8 \\
\hline $\begin{array}{l}\text { Mochache K et al. } \\
2018\end{array}$ & Kenya & $\mathrm{HI}$ & cohort & 255 & & $E P D S \geq 10$ & $38.40 \%$ & 8 \\
\hline Thai A et al. 2016 & $\begin{array}{l}\text { South } \\
\text { Africa }\end{array}$ & Community & longitudinal & 1238 & All trim & $E P D S>=13$ & $39.50 \%$ & 7 \\
\hline
\end{tabular}


with a 95\% confidence interval was used to assess the association between antenatal depression and associated factors. The analysis was done using Stata version 14 software [36].

\section{Protocol registration}

The review protocol has been registered in PROSPERO with protocol number CRD42018106717.

\section{Result}

\section{Search}

We conducted an electronic literature search and identified 175 unique records of journal articles and $124 \mathrm{du}-$ plicates that were removed. After meticulous review of the titles and abstracts, we excluded 22 articles because of difference in population under study [37-42] and outcome of the study [43-45], full text not found and study area not known [46-50], reviews $[5,19,51-53]$ and conducted in restricted population [54, 55]. We obtained full-text copies of 29 records for further review. Of those full-text articles, one article [56] was excluded because of poor quality. Finally, 28 articles with an overall sample size of 17, 938 were included in the narrative review and Meta-analysis (Fig. 1).

\section{Included study characteristics}

The sample size across the studies ranges from 109 [57] to 2086 [58] pregnant mothers. The selected studies for Meta-analysis were geographically diverse and included 10 African countries with the majority (9 studies) of the studies from Ethiopia [17, 27, 30, 31, 45, 59-62] followed by South Africa, which contains five studies $[18,57,63-65]$. In terms of the study setting majority of the included studies [20] were health institution based $[8,13,15,16,27,57,59-64,66-72]$ and the rest were community-based [17, 18, 30, 31, 45, 58, 65, 73]. Moreover, 21 studies used cross-sectional $[8,15-18,27,30$, $31,57,59-64,66-70,73]$, six studies used cohort [13, $45,58,71,72]$, and one study used longitudinal study design [65].

The included studies used different tools for screening depression. The tool used by the majority [11] of the studies was EPDS at a different cut off value [18, 27, 30, $31,62,63,65,69,70,72,73]$ followed by PHQ [5] [13, 17, 45, 71]. Most of the included studies [13] screened depression in all trimesters of pregnancy $[8,16,18,27$, $30,59,60,62,64-66,69,70]$ followed by screening in the third trimester of pregnancy, which was applied in 8 studies $[13,15,31,61,63,71,73]$. The prevalence of depression among the included studies ranges from $8.3 \%$ [15] to 78\% [16] and all of the included studies have high quality based on NOS (Table 1).

\section{Pooled prevalence of antenatal depression}

The pooled prevalence of antenatal depression in Africa from 28 studies was found to be $26.3 \%$ (95\% CI: 22.2 , $\left.30.4 \% ; I^{2}=97.7 \%\right)$.As eggers test was found significant, the final pooled prevalence was corrected for Duval and Tweedie's trim and fill analysis and was $26.3 \%$ (95\% CI; 22.2, 30.4\%) (Figs. 2 and 3). The meta-regression was

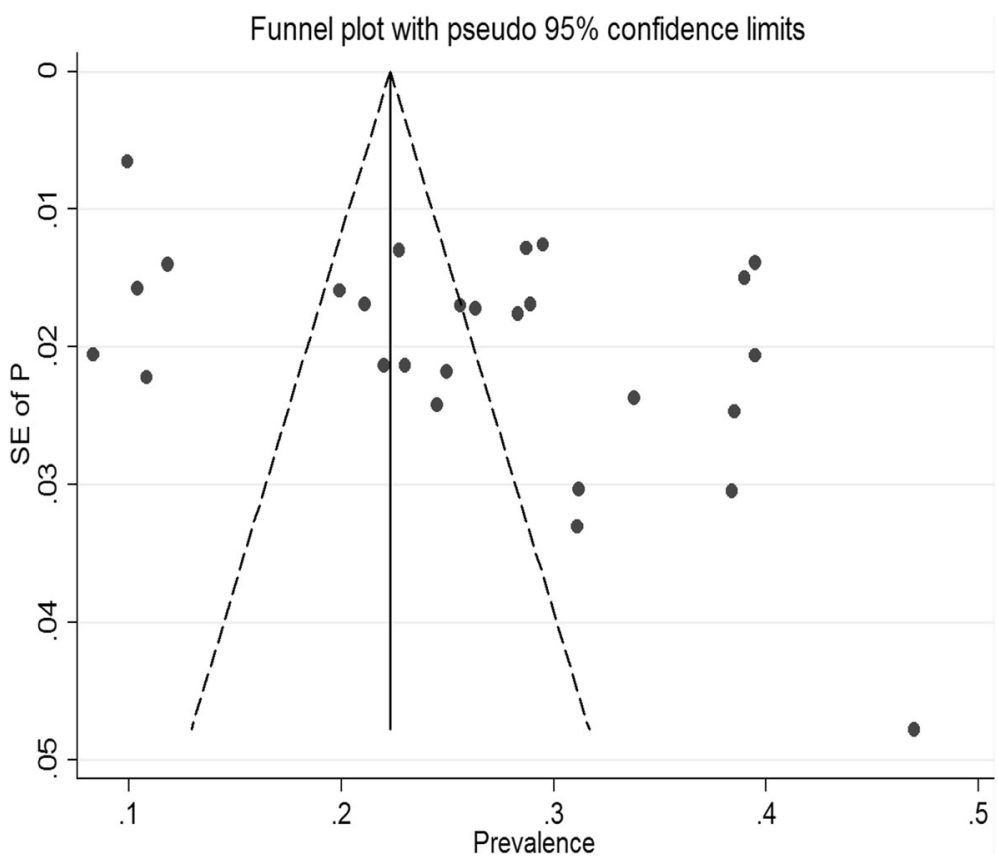

Fig. 2 Funnel plot testing publication bias (random, $N=27$ ) 
Filled funnel plot with pseudo 95\% confidence limits

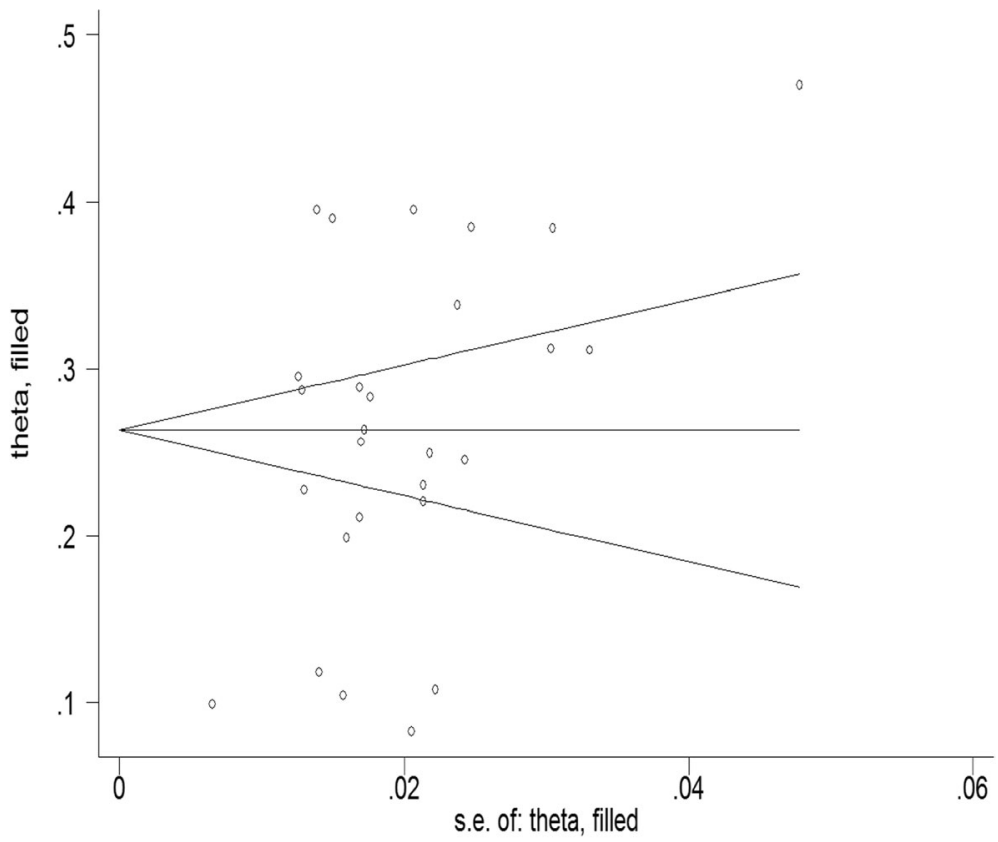

Fig. 3 Filled funnel plot after adjusting for publication bias

conducted to identify study characteristics accounted for heterogeneity. The pooled prevalence was higher at 27.01\% (95\% CI: 21.15, 32.87\%)in Sub Saharan Africa (SSA) than the pooled rate in Ethiopia at 24.91\% (95\% CI: 20.35, 29.46\%) (Fig. 4).

Besides, subgroup analysis was done based on the income of countries, time of depression measurement, study setting, study design, year of publication, and tool used to screen depression. Based on the time of screening for depression in the course of pregnancy, the highest pooled prevalence of antenatal depression was observed in the second trimester, 32.20\% (95\% CI: 26.13, $38.28 \%)$. On the other hand, a significantly lowest prevalence of was found from a single study with a screening time in the first trimester, 9.90\% (95\% CI: 8.60, 11.20\%). Depending on the study setting, the pooled prevalence of antenatal depression for 19 health institution based studies was 26.77\% (95\%: 22.54, 30.99\%).

Based on the study design, the pooled prevalence of antenatal depression for seven studies, which applied longitudinal study design was higher, at $28.49 \%$ (95\% CI: $18.47,38.52 \%)$, as compared to those using crosssectional study designs. In terms of the sample size, the pooled prevalence of antenatal depression for 19 studies with a sample size above 384 was $27.43 \%$ (95\% CI: 22.54 , $32.31 \%)$. Concerning the year of publication, the highest pooled prevalence was observed from 4 studies published between 2010 and 2012, 39.44\% (95\% CI: 37.37, $41.50 \%)$. On the other hand, the lowest pooled prevalence of $9.46 \%$ (95\% CI: 6.46\%, 12.46) was observed from studies published between 2007 and 2009. Depending on the screening tool used, the pooled prevalence of antenatal depression was the highest for 11 studies that used EPDS ( $\mathrm{PP}=28.89 \%$; 95\% CI: 22.79, 34.98\%) (Table 2).

Sensitivity analysis was completed after excluding the study with the highest prevalence [16], and it showed that omission of any of the incorporated studies did not change the pooled prevalence of antenatal depression (Fig. 5).

Based on the result from Meta-analysis of identified risk factors, economic difficulties $[\mathrm{POR}=1.87$ (95\% CI: $\left.1.25,2.78), I^{2}=88.1 \%\right]$, unfavorable marital condition $\left[\mathrm{POR}=4.17\right.$ (95\% CI:1.75, 9.94), $\left.I^{2}=81.2 \%\right]$, poor support from relatives $\left[\mathrm{POR}=1.36(95 \% \mathrm{CI}: 1.18,1.56), \mathrm{I}^{2}=\right.$ $78.0 \%$, bad obstetric history [POR $=2.30$ (95\% CI:1.81, $\left.2.92), \mathrm{I}^{2}=81.7 \%\right]$, and having history of mental health problem $\quad\left[\mathrm{POR}=2.97\right.$ (95\% CI:1.74, 5.06), $\left.\mathrm{I}^{2}=92.0 \%\right]$ were the major factors associated with antenatal depression (Figs. 6 and 7).

\section{Discussion}

The current review assessed the prevalence of antenatal depression and its associated factors in Africa. Our review showed the pooled prevalence of depression among African pregnant women was $26.3 \%$, and it is significantly associated with economic difficulties, poor support from relatives, bad obstetric history (such as 


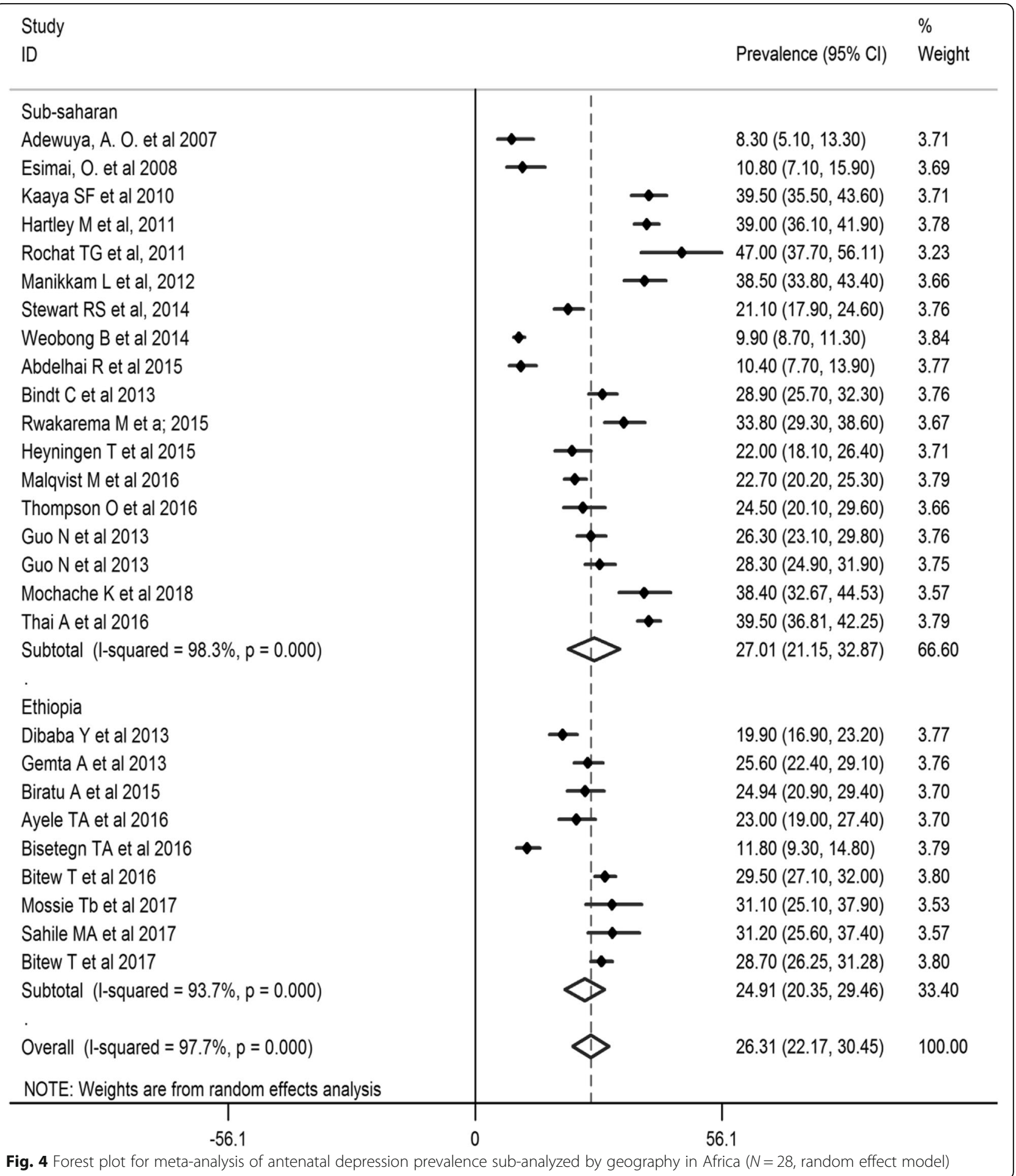


Table 2 Sub-analysis of studies on antenatal depression conducted in Africa ( $N=27$, random effect)

\begin{tabular}{|c|c|c|c|}
\hline Variable for sub-analysis & Number of studies & Sample size $(N)$ & Pooled prevalence $(95 \% \mathrm{Cl})$ random effect model \\
\hline \multicolumn{4}{|l|}{ The income of the countries } \\
\hline Low-income & 12 & 7115 & $26.54(22.23,30.85)$ \\
\hline Middle-income & 15 & 7775 & $26.13(19.60,32.64)$ \\
\hline \multicolumn{4}{|l|}{ Time of depression measurement } \\
\hline 1st trimester & 1 & 2086 & $9.90(8.60,11.20)$ \\
\hline 2nd trimester & 5 & 3803 & $32.20(26.13,38.28)$ \\
\hline 3rd trimester & 8 & 4312 & $25.39(20.15,30.65)$ \\
\hline All trimester & 13 & 4689 & $25.71(19.30,32.11)$ \\
\hline \multicolumn{4}{|l|}{ Study setting } \\
\hline Community-based & 8 & 7891 & $25.11(16.52,33.69)$ \\
\hline Health institution based & 19 & 6999 & $26.77(22.54,30.99)$ \\
\hline \multicolumn{4}{|l|}{ Study design } \\
\hline Longitudinal & 7 & 5353 & $28.49(18.47,38.52)$ \\
\hline Cross sectional & 20 & 9537 & $25.50(21.16,29.84)$ \\
\hline \multicolumn{4}{|l|}{ Sample size } \\
\hline$<=384$ & 8 & 1626 & $23.59(15.49,31.69)$ \\
\hline$>384$ & 19 & 14,757 & $27.43(22.54,32.31)$ \\
\hline \multicolumn{4}{|l|}{ Year of Publication } \\
\hline 2007-2009 & 2 & 375 & $9.46(6.46,12.46)$ \\
\hline 2010-2012 & 4 & 2118 & $39.44(37.37,41.50)$ \\
\hline 2013-2015 & 11 & 7525 & $22.75(17.32,28.18)$ \\
\hline $2016-2018$ & 10 & 6740 & $27.92(22.41,33.43)$ \\
\hline \multicolumn{4}{|l|}{ Type of screening tool used } \\
\hline EPDS & 11 & 6898 & $28.89(22.79,34.98)$ \\
\hline PHQ-9 & 5 & 4578 & $28.54(27.23,29.84)$ \\
\hline Diagnostic tools (DSM-IV,CIS-R) & 3 & 665 & $25.22(8.33,42.11)$ \\
\hline Other (CES-D, SRQ, HSC, BDI) & 8 & 4617 & $21.96(14.30,29.62)$ \\
\hline
\end{tabular}

previous pregnancy loss and complications), unfavorable marital condition, and history of mental health problems.

The result was consistent with a review conducted in low-and middle-income countries, which showed a pooled prevalence of $25.3 \%$ [74]. The pooled prevalence of antenatal depression from this review was found to be higher than other reviews done in Africa and low-and middle-income countries, which showed that the weighted mean prevalence of common mental health disorders to be 11.3 and $15.6 \%$, respectively [12, 75]. This might indicate that antenatal depression is increasing over time. Our estimate was also higher than another systematic review and meta-analysis done in developed countries, which showed the pooled prevalence at the first, second, and third trimesters to be 7.4, 12.8, and $12 \%$, respectively [10]. The higher pooled prevalence in our review could be mothers in Africa are exposed to additional socio-economic problems and stressful life events than mothers from developed countries, which increases their risk of developing depression.

The odds of having antenatal depression among women who have economic difficulties was found to be 1.87. This result was consistent with other systematic reviews published in Ethiopia, low-and middle-income countries, and worldwide [5, 12, 76, 77]. The finding was also supported by another large scale prospective cohort study conducted to assess the association between low socioeconomic status and antenatal depression [78]. Mothers in such economic difficulties would worry about the family and the coming babies' basic needs, and this can also be related to family food insecurity, which is highly associated with antenatal depression [31, 79].

This review showed that unfavorable marital condition (explained as divorce, relationship difficulties, being single at the time of pregnancy, marital conflict) was 


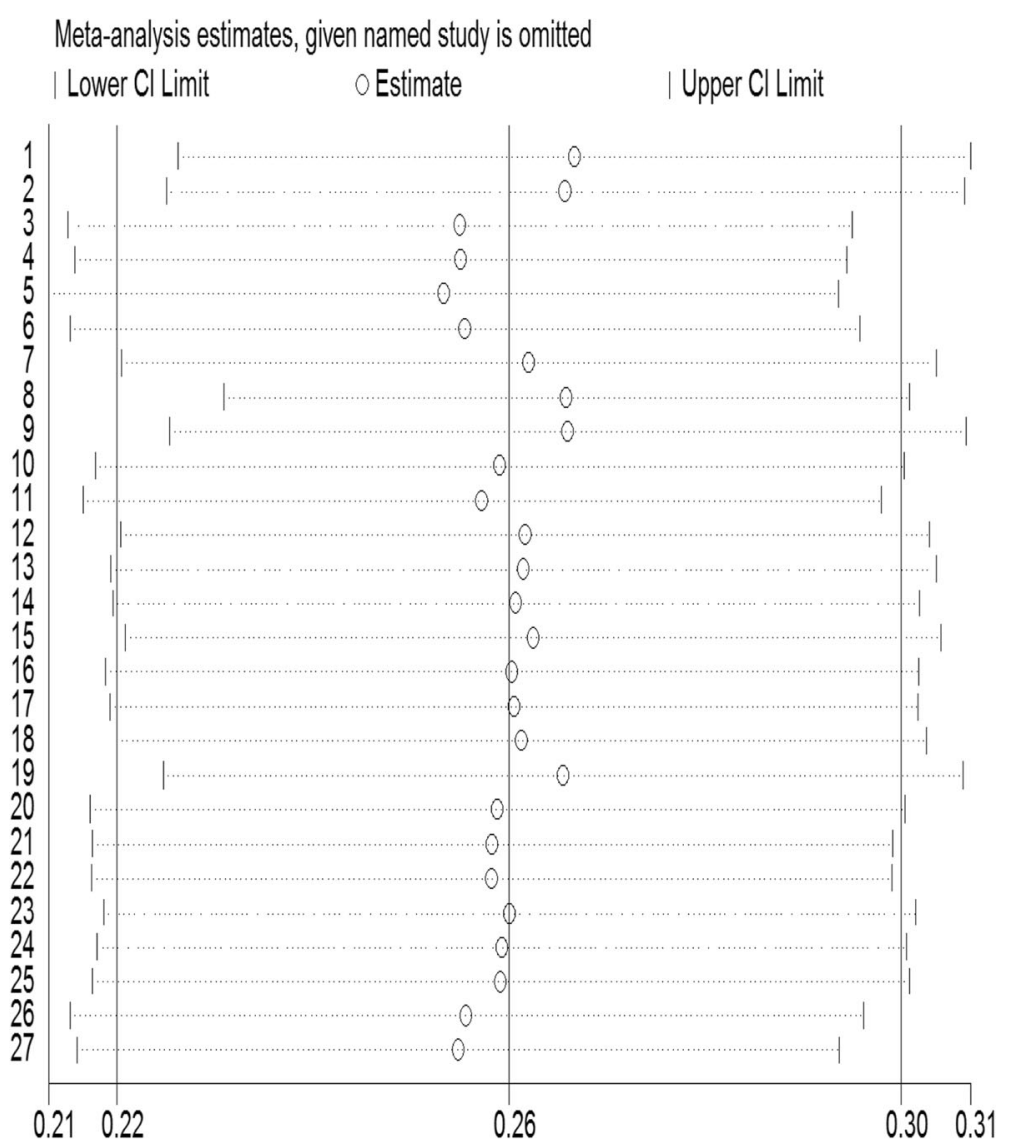

Fig. 5 Sensitivity analysis for studies included in the meta-analysis

significantly associated with increased risk of antenatal depression by 4.17 times. A similar association was found from other systematic reviews done in Ethiopia and other low-and middle-income countries [5, 12]. This might be because of a lack of support from husband at the time of pregnancy as those women who receive husbands' support during their pregnancy may be well empowered to deal with their pregnancy and their home responsibility. Another reason could be those women with unfavorable marital conditions might live alone, practice more loneliness, and low self-confidence that may predispose them to depression.

This review also showed that there was an increased risk of antenatal depression among women who had poor support from relatives, which is supported by other previous reviews $[12,76,80]$. The possible reason could be because social support reduces stressful life events by providing informational, instrumental, and emotional support during pregnancy $[80,81]$. Perhaps, the objective evaluation of social support that women received during pregnancy may be challenging as it has been noticed that depressed women tend to feel less supported than they objectively are [82]. Women with a bad obstetric history were found to be at an increased risk of antenatal depression by an odds of 2.30 times. This result was similar to other reviews done in Ethiopia [5,77] and worldwide [80]. This is directly associated with the mother's fear of facing similar complications in her current pregnancy like the previous one.

Women with a history of mental health problems also had three-fold increased odds of developing antenatal depression in the current pregnancy as compared to those who did not report such history. This result was supported by other reviews done in Ethiopia $[5,77]$ and worldwide [80]. Having a history of mental disorders, including depressive episodes, may indicate the mother's biological vulnerability to the disorder, which may indirectly cause pregnancy mood changes in the current pregnancy [83].

The strength of this review is that it included only high-quality studies that scored $\geq$ seven based on the NOS criteria, and this may increase the reliability and validity of the findings. Besides, all available observational studies in Africa that satisfied our inclusion criteria were included, and this would increase the review generalizability. However, the use of screening 


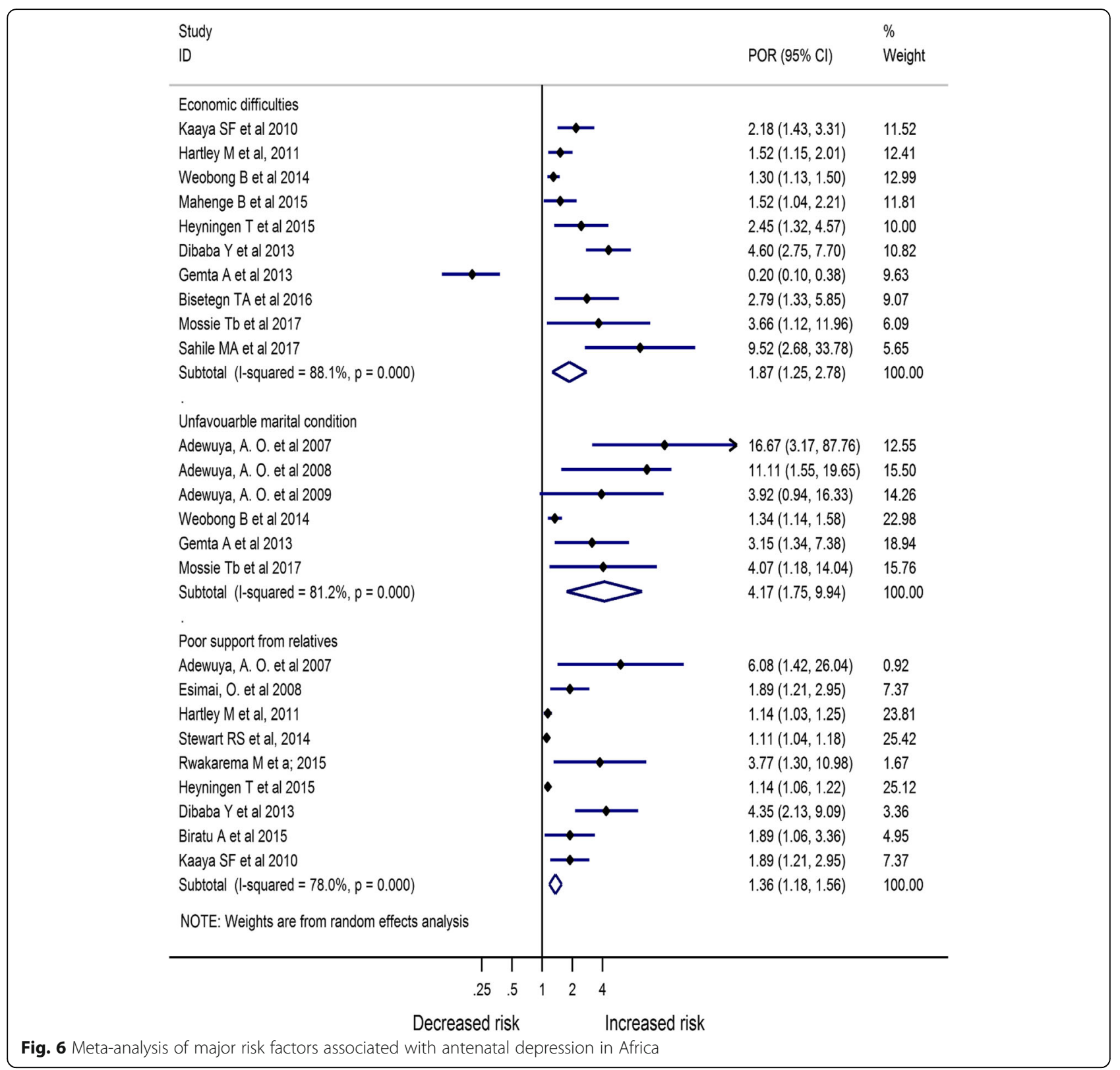

instruments in prevalence studies relies on symptom identification rather than diagnosis, and this affects the validity of the review as screening tools over or underestimate the actual effect estimate. Though a subgroup and random-effect meta-analysis were conducted to minimize the effect of heterogeneity, the prevalence estimates might still be affected by the inherent heterogeneity of included studies, which may be due to the difference in the study area, methodology, study period and the type of screening tool used in the studies. Therefore, policymakers should make the interpretations of these results with caution by considering this inherent heterogeneity. Further standardization of screening tool that would be used in different countries might help to minimize the observed heterogeneity. Moreover, excluding works of literature that are not published in the English language may create selection bias. The clinical importance of this review is that it clearly showed that depression during pregnancy is highly prevalent and needs to be targeted for screening and early treatment.

\section{Conclusion}

We found that one in four mothers had antenatal depression, and it is independently associated with a mother's economic difficulties, poor support from relatives, unfavorable marital condition, previous history of 


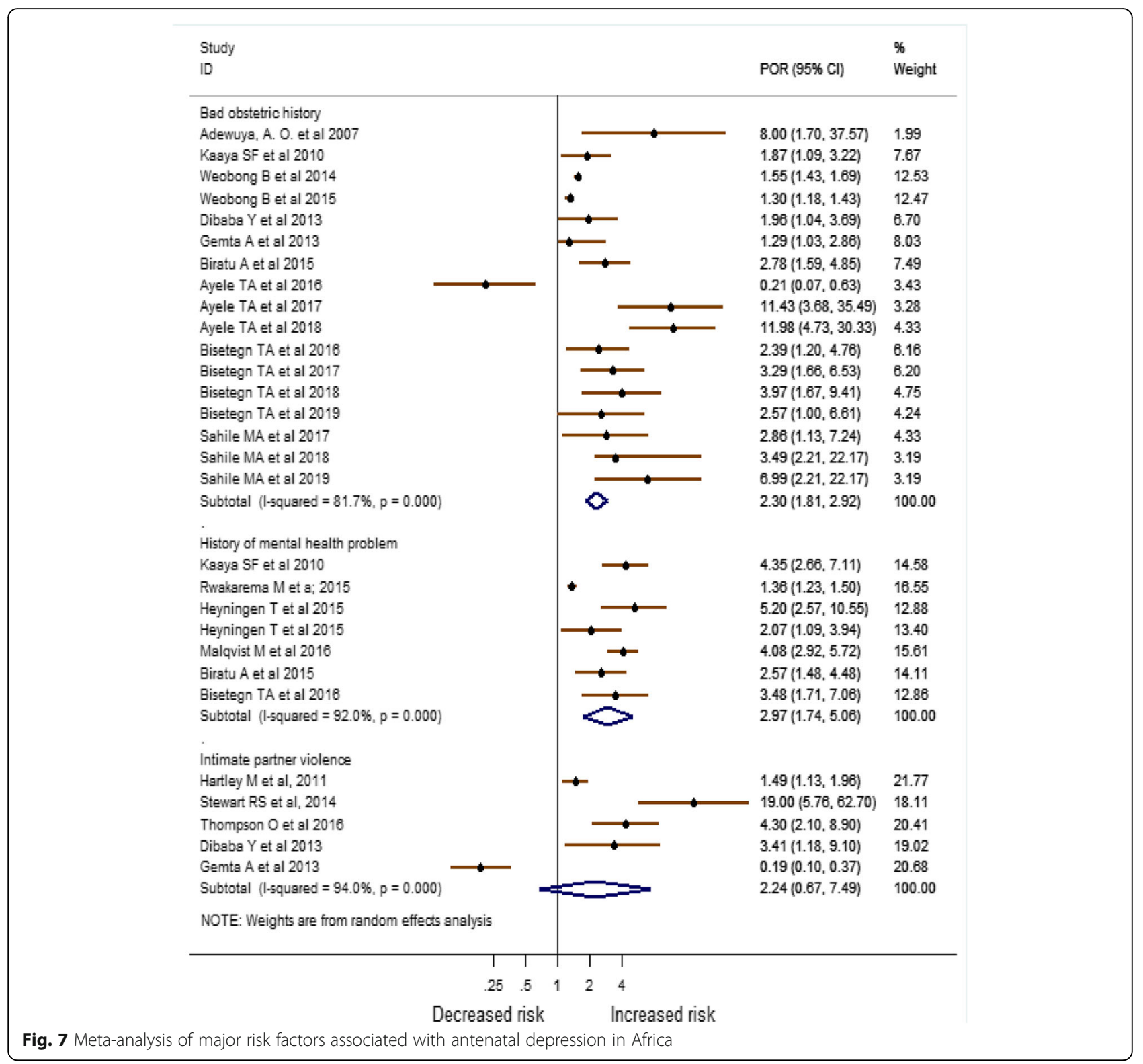

mental disorder, and bad obstetric history. Depression screening during pregnancy follow up in African health facilities is highly relevant to early detect and intervene in women's at risk of antenatal depression. This would help the achievement of sustainable development goal five (SDG-5) through improving maternal mental health.

\section{Abbreviations}

BDI: Beck Depression Inventory; Cl: Confidence Interval; DSM-IV: Diagnostic and Statistical Manual of mental disorders version 4; EPDS: Edinburgh Postnatal Depression Scale; HADS: Hospital Anxiety and Depression Scale; LAMICs: Low And Middle-Income Countries; NOS: Newcastle Ottawa Scale; PHQ: Patient Health Questionnaire 9; POR: Pooled Odds Ratio;

PRISMA: Reporting Items for Systematic reviews and Meta-Analysis; SDG5: Sustainable Development Goal 5; SSA: Sub Saharan Africa; WHO: World Health Organization

\section{Acknowledgments}

We would like to thank Angie Willcocks from the University of South Australia for her expert advice and proofreading of this review.

Consent for publication.

Not applicable.

Authors' contribution

AFD, TYA, AGB, HFW: conceived the design; AFD develop the search strategy: AFD, TYA, AGB, HFW: searched, screened, and appraised the studies, and extract the data: AFD analyzed the data; AFD, TYA, AGB, HFW: drafted the manuscript. All authors read and approved the final manuscript for publication.

Funding

Not applicable. 


\section{Availability of data and materials}

All the materials and data on which the findings of this review are based are presented within the manuscript.

\section{Ethics approval and consent to participate}

Since this study is an investigation of the already available literature for the public, there is no need for ethical approval.

\section{Competing interests}

All authors declared that there is no competing interest.

\section{Author details}

${ }^{1}$ University of Gondar, College of Medicine and Health Sciences, Institute of Public Health, Department of Epidemiology and Biostatistics, Gondar, Ethiopia. ${ }^{2}$ School of Public Health, College of Medicine and Public Health, Flinders University, Adelaide, Australia.

\section{Received: 26 February 2019 Accepted: 7 April 2020 Published online: 28 April 2020}

\section{References}

1. Understanding mental illness; a guide to brain disorders, medication, and therapy. 2011

2. WHO Guidelines Approved by the Guidelines Review Committee. MhGAP Intervention Guide for Mental, Neurological and Substance Use Disorders in Non-Specialized Health Settings: Mental Health Gap Action Programme (mhGAP). Geneva: World Health Organization World Health Organization; 2010.

3. WHO. Depression and Other Common Mental Disorders, Global Health Estimates. 2017.

4. GBD. Disease and Injury Incidence and Prevalence Collaborators, and others Global, regional, and national incidence, prevalence, and years lived with disability for 310 diseases and injuries, 1990-2015: a systematic analysis for the Global Burden of Disease Study 2015. Lancet. 2016;388:10053.

5. Mersha AG, Abebe SA, Sori LM, Abegaz TM. Prevalence and associated factors of perinatal depression in Ethiopia: a systematic review and metaanalysis. Depress Res Treat. 2018.

6. Abujilban SK, Abuidhail J, Al-Modallal H, Hamaideh S, Mosemli O. Predictors of antenatal depression among Jordanian pregnant women in their third trimester. Health Care Women Int. 2014:35(2):200-15.

7. Deecher D, Andree TH, Sloan D, Schechter LE. From menarche to menopause: exploring the underlying biology of depression in women experiencing hormonal changes. Psychoneuroendocrinology. 2008;33(1):317.

8. Abdelhai R, Mosleh $\mathrm{H}$. Screening for antepartum anxiety and depression and their association with domestic violence among Egyptian pregnant women. J Egypt Public Health Assoc. 2015;90(3):101-8.

9. Rahman A, lqbal Z, Bunn J, Lovel H, Harrington R. Impact of maternal depression on infant nutritional status and illness: a cohort study. Arch Gen Psychiatry. 2004;61(9):946-52

10. Bennett HA, Einarson A, Taddio A, Koren G, Einarson TR. Prevalence of depression during pregnancy: systematic review. Obstet Gynecol. 2004: 103(4):698-709.

11. Grote NK, Bridge JA, Gavin AR, Melville JL, lyengar S, Katon WJ. A metaanalysis of depression during pregnancy and the risk of preterm birth, low birth weight, and intrauterine growth restriction. Arch Gen Psychiatry. 2010; 67.

12. Fisher J. Cabral de Mello M, Patel V, Rahman a, Tran T, Holton S, et al. prevalence and determinants of common perinatal mental disorders in women in low- and lower-middle-income countries: a systematic review. Bull World Health Organ. 2012;90(2):139-49H.

13. Bindt C, Guo N, Bonle MT, Appiah-Poku J, Hinz R, Barthel D, et al. No association between antenatal common mental disorders in low-obstetric risk women and adverse birth outcomes in their offspring: results from the CDS study in Ghana and cote D'Ivoire. PLoS One. 2013;8(11):e80711.

14. Assefa GW. Prevalence and factors associated with antenatal depression among women following antenatal care at Shashemane health facilities, South Ethiopia. Ann Glob Health. 2015;81(1):90.

15. Adewuya AO, Ola BA, Aloba OO, Dada AO, Fasoto OO. Prevalence and correlates of depression in late pregnancy among Nigerian women. Depression Anxiety. 2007;24(1):15-21.
16. Mahenge B, Stockl H, Likindikoki S, Kaaya S, Mbwambo J. The prevalence of mental health morbidity and its associated factors among women attending a prenatal clinic in Tanzania. Int J Gynaecol Obstet. 2015;130(3): 261-5.

17. Bitew T, Hanlon C, Kebede E, Medhin G, Fekadu A. Antenatal depressive symptoms and maternal health care utilisation: a population-based study of pregnant women in Ethiopia. BMC Pregnancy Childbirth. 2016;16(1):301.

18. Hartley M, Tomlinson M, Greco E, Comulada WS, Stewart J, le Roux I, et al. Depressed mood in pregnancy: prevalence and correlates in two Cape Town peri-urban settlements. Reprod Health. 2011;8(1):9.

19. Alder J, Fink N, Bitzer J, Hösli I, Holzgreve W. Depression and anxiety during pregnancy: a risk factor for obstetric, fetal and neonatal outcome? A critical review of the literature. J Matern Fetal Neonatal Med. 2007:20(3):189-209.

20. Chang HY, Keyes KM, Lee KS, Choi IA, Kim SJ, Kim KW, et al. Prenatal maternal depression is associated with low birth weight through shorter gestational age in term infants in Korea. Early Hum Dev. 2014;90(1):15-20.

21. Nasreen HE, Kabir ZN, Forsell Y, Edhborg M. Low birth weight in offspring of women with depressive and anxiety symptoms during pregnancy: results from a population based study in Bangladesh. BMC Public Health. 2010; 10(1):515.

22. Rao D, Kumar S, Mohanraj R, Frey S, Manhart LE, L. Kaysen D. The impact of domestic violence and depressive symptoms on preterm birth in South India. Soc Psychiatry Psychiatr Epidemiol. 2016;51(2):225-32.

23. Saeed A, Raana T, Saeed AM, Humayun A. Effect of antenatal depression on maternal dietary intake and neonatal outcome: a prospective cohort. Nutr J. 2016;15(1):64.

24. Lee AM, Lam SK, Lau SMSM, Chong CSY, Chui HW, Fong DYT. Prevalence, course, and risk factors for antenatal anxiety and depression. Obstet Gynecol. 2007;110(5):1102-12.

25. Orr ST, James SA, Blackmore PC. Maternal prenatal depressive symptoms and spontaneous preterm births among African-American women in Baltimore, Maryland. Am J Epidemiol. 2002;156(9):797-802.

26. Evans J, Heron J, Patel RR, Wiles N. Depressive symptoms during pregnancy and low birth weight at term: longitudinal study. Br J Psychiatry. 2007:191.

27. Biratu A, Haile D. Prevalence of antenatal depression and associated factors among pregnant women in Addis Ababa, Ethiopia: a cross-sectional study. Reprod Health. 2015;12:99.

28. Black MM, Baqui AH, Zaman K, McNary SW, Le K, Arifeen SE, et al. Depressive symptoms among rural Bangladeshi mothers: implications for infant development. J Child Psychol Psychiatry. 2007:48(8):764-72.

29. Ajinkya S, Jadhav PR, Srivastava NN. Depression during pregnancy: prevalence and obstetric risk factors among pregnant women attending a tertiary care hospital in Navi Mumbai. Ind Psychiatry J. 2013;22(1):37-40.

30. Bisetegn TA, Mihretie G, Muche T. Prevalence and predictors of depression among pregnant women in debretabor town, northwest Ethiopia. PLoS One. 2016;11(9)

31. Dibaba Y, Fantahun M, Hindin MJ. The association of unwanted pregnancy and social support with depressive symptoms in pregnancy: evidence from rural southwestern Ethiopia. BMC Pregnancy Childbirth. 2013;13.

32. Liberati A, Altman DG, Tetzlaff J, Mulrow C, Gøtzsche PC, loannidis JP, et al. The PRISMA statement for reporting systematic reviews and meta-analyses of studies that evaluate health care interventions: explanation and elaboration. PLoS Med. 2009:6(7):e1000100.

33. Wells G, Shea B, O'connell D, Peterson J, Welch V, Losos M, et al. The Newcastle-Ottawa Scale (NOS) for assessing the quality of nonrandomised studies in meta-analyses. Ottawa Hospital Research Institute, 2014. oxford. ASp; 2015.

34. Borenstein M, Hedges LV, Higgins JP, Rothstein HR. Introduction to metaanalysis: John Wiley \& Sons; 2011

35. Duval S, Tweedie R. A nonparametric "trim and fill" method of accounting for publication bias in meta-analysis. J Am Stat Assoc. 2000;95(449):89-98.

36. Stata A. Stata Base reference manual release 14. 2015.

37. Dailey DE, Humphreys JC. Social stressors associated with antepartum depressive symptoms in low-income African American women. Public Health Nurs. 2011;28(3):203-12

38. Jallo N, Elswick RK Jr, Kinser P, Masho S, Price SK, Svikis DS. Prevalence and predictors of depressive symptoms in pregnant African American women. Issues Mental Health Nurs. 2015:36(11):860-9.

39. Luke S, Salihu HM, Alio AP, Mbah AK, Jeffers D, Berry EL, et al. Risk factors for major antenatal depression among low-income African American women. J Women's Health. 2009;18(11):1841-6. 
40. Jackson FM, Rowley DL, Curry OT. Contextualized stress, global stress, and depression in well-educated, pregnant, African-American women. Women's Health Issues. 2012;22(3):e329-e36.

41. Luiza JW, Gallaher MJ, Powers RW. Urinary cortisol and depression in early pregnancy: role of adiposity and race. BMC Pregnancy Childbirth. 2015;15(1):30.

42. Shen JJ, Lin F, Jackson T. Risk of prenatal depression: differences by race. Ethnicity Dis. 2010;20(1):35-9.

43. Bennett IM, Schott W, Krutikova S, Behrman JR. Maternal mental health, and child growth and development, in four low-income and middle-income countries. J Epidemiol Community Health. 2015;70(2):168-73.

44. Jebena MG, Taha M, Nakajima M, Lemieux A, Lemessa F, Hoffman R, et al. Household food insecurity and mental distress among pregnant women in Southwestern Ethiopia: A cross sectional study design. BMC Pregnancy Childbirth. 2015;15(1).

45. Bitew T, Hanlon C, Kebede E, Honikman S, Fekadu A. Antenatal depressive symptoms and perinatal complications: a prospective study in rural Ethiopia. BMC Psychiatr. 2017;17(1):301.

46. Glover V. Maternal depression, anxiety and stress during pregnancy and child outcome; what needs to be done. Best Pract Res Clin Obstet Gynaecol. 2014;28(1):25-35.

47. Gerardin P. Characteristics and clinical consequences of prenatal depression Main results of a prospective case-control study on perinatal depression from pregnancy to one year-old infant. Neuropsychiatrie de l'Enfance et de I'Adolescence. 2012;60(2):138-46.

48. Freeman MP. Perinatal psychiatry: risk factors, treatment data, and specific challenges for clinical researchers. J Clin Psychiatry. 2008;69(4):633-4.

49. Hurst J, Zeanah P, Lewis L, Mills K. Examining the association between nutrition and psychosocial factors in first-time pregnant women: a crosssectional pilot study. Int J Disabil Hum Dev. 2012;11(4):343-50.

50. Hwa-Froelich DA, Loveland Cook CA, Flick LH. Maternal sensitivity and communication styles: Mothers with depression: Journal of Early Intervention. 31 (1) (pp 44-66), 2008. Date of Publication: December 2008:; 2008.

51. Fuller-Tyszkiewicz M, Skouteris $H$, Watson BE, Hill B. Body dissatisfaction during pregnancy: a systematic review of cross-sectional and prospective correlates. J Health Psychol. 2013;18(11):1411-21.

52. Leung BM, Kaplan BJ. Perinatal depression: prevalence, risks, and the nutrition link--a review of the literature. J Am Diet Assoc. 2009;109(9):1566-75.

53. Hanlon C. Maternal depression in low- and middle-income countries. Int Health. 2013;5(1):4-5

54. Rochat T, Tomlinson M, Newell M, Stein A. Depression among pregnant women testing for HIV in rural South Africa: Implications for VCT. 9th International AIDS Impact Conference; Botswana. 2009.

55. Osok J, Kigamwa P, Vander Stoep A, Huang K-Y, Kumar M. Depression and its psychosocial risk factors in pregnant Kenyan adolescents: a crosssectional study in a community health Centre of Nairobi. BMC Psychiatry. 2018;18(1):136.

56. Tsai AC, Tomlinson M, Comulada WS, Rotheram-Borus MJ. Food insufficiency, depression, and the modifying role of social support: evidence from a population-based, prospective cohort of pregnant women in periurban South Africa. Soc Sci Med. 2016;151:69-77.

57. Rochat TJ, Tomlinson M, Barnighausen T, Newell ML, Stein A. The prevalence and clinical presentation of antenatal depression in rural South Africa. J Affect Disord. 2011;135(1-3):362-73.

58. Weobong B, Soremekun S, Ten Asbroek AH, Amenga-Etego S, Danso S, Owusu-Agyei $\mathrm{S}$, et al. Prevalence and determinants of antenatal depression among pregnant women in a predominantly rural population in Ghana: the DON population-based study. J Affect Disord. 2014;165:1-7.

59. Ayele TA, Azale T, Alemu K, Abdissa Z, Mulat H, Fekadu A. Prevalence and associated factors of antenatal depression among women attending antenatal Care Service at Gondar University Hospital, Northwest Ethiopia. PLoS One. 2016;11(5):e0155125.

60. Mossie TB, Sibhatu AK, Dargie A, Ayele AD. Prevalence of antenatal depressive symptoms and associated factors among pregnant women in Maichew, North Ethiopia: an institution based study. Ethiop J Health Sci. 2017;27(1):59-66.

61. Sahile MA, Segni MT, Awoke T, Bekele D. Prevalence and predictors of antenatal depressive symptoms among women attending Adama hospital antenatal clinic, Adama, Ethiopia. Int J Nurs Midwifery. 2017;9(5):58-64.

62. Gemta WA. Prevalence and factors associated with antenatal depression among women following antenatal care at Shashemane health facilities, South Ethiopia. Ann Glob Health. 2015;1(81):90.
63. Manikkam L, Burns JK. Antenatal depression and its risk factors: an urban prevalence study in KwaZulu-Natal. S Afr Med J. 2012;102.

64. Heyningen TV, Myer L, Onah M, Tomlinson M, Field S, Honikman S. Antenatal depression and adversity in urban South Africa. J Affect Disord. 2016;203:121-9.

65. Tsai AC, Tomlinson M, Comulada WS, Rotheram-Borus MJ. Intimate partner violence and depression symptom severity among south African women during pregnancy and postpartum: population-based prospective cohort study. PLoS Med. 2016;13(1):e1001943.

66. Esimai O, Fatoye F, Quiah A, Vidal O, Momoh R. Antepartum anxiety and depressive symptoms: a study of Nigerian women during the three trimesters of pregnancy. J Obstet Gynaecol. 2008;28.

67. Kaaya SF, Mbwambo JK, Kilonzo GP, Van Den Borne H, Leshabari MT, Fawzi MC, et al. Socio-economic and partner relationship factors associated with antenatal depressive morbidity among pregnant women in Dar Es Salaam, Tanzania. Tanzan J Health Res. 2010;12(1):23-35.

68. Stewart RC, Umar E, Tomenson B, Creed F. A cross-sectional study of antenatal depression and associated factors in Malawi. Arch Women's Mental Health. 2014;17(2):145-54.

69. Rwakarema M, Premji SS, Nyanza EC, Riziki P, Palacios-Derflingher L. Antenatal depression is associated with pregnancy-related anxiety, partner relations, and wealth in women in northern Tanzania: a cross-sectional study. BMC Womens Health. 2015;15:68

70. Thompson O, Ajayi I. Prevalence of antenatal depression and associated risk factors among pregnant women attending antenatal clinics in Abeokuta north local government area, Nigeria Depression Research and Treatment 2016;2016:4518979.

71. Guo N, Bindt C, Te Bonle M, Appiah-Poku J, Hinz R, Barthel D, et al. Association of antepartum and postpartum depression in Ghanaian and Ivorian women with febrile illness in their offspring: a prospective birth cohort study. Am J Epidemiol. 2013;178(9):1394-402.

72. Mochache K, Mathai M, Gachuno O, Vander Stoep A, Kumar M. Depression during pregnancy and preterm delivery: a prospective cohort study among women attending antenatal clinic at Pumwani maternity hospital. Ann General Psychiatry. 2018;17(1):31.

73. Målqvist M, Clarke K, Matsebula T, Bergman M, Tomlinson M. Screening for antepartum depression through community health outreach in Swaziland. Community Health. 2016;41(5):946-52.

74. Gelaye B, Rondon MB, Araya R, Williams MA. Epidemiology of maternal depression, risk factors, and child outcomes in low-income and middleincome countries. Lancet Psychiatry. 2016;3(10):973-82.

75. Sawyer A, Ayers S, Smith H. Pre-and postnatal psychological wellbeing in Africa: a systematic review. J Affect Disord. 2010;123(1-3):17-29.

76. Lancaster CA, Gold KJ, Flynn HA, Yoo H, Marcus SM, Davis MM. Risk factors for depressive symptoms during pregnancy: a systematic review. Am J Obstet Gynecol. 2010;202(1):5-14.

77. Getinet W, Amare T, Boru B, Shumet S, Worku W, Azale T. Prevalence and risk factors for antenatal depression in Ethiopia: systematic review. Depress Res Treat 2018;2018.

78. Verbeek T, Bockting C, Beijers C, Meijer J, Van Pampus M, Burger H. Low socio-economic position increases the adverse effect of negative life events on anxiety and depression during pregnancy. Eur Psychiatr. 2015;30:742.

79. Abrahams Z, Lund C, Field S, Honikman S. Factors associated with household food insecurity and depression in pregnant south African women from a low socio-economic setting: a cross-sectional study. Soc Psychiatry Psychiatr Epidemiol. 2018;53(4):363-72.

80. Biaggi A, Conroy S, Pawlby S, Pariante CM. Identifying the women at risk of antenatal anxiety and depression: a systematic review. J Affect Disord. 2016;191:62-77.

81. Elsenbruch S, Benson S, Rücke M, Rose M, Dudenhausen J, PincusKnackstedt MK, et al. Social support during pregnancy: effects on maternal depressive symptoms, smoking and pregnancy outcome. Hum Reprod. 2006;22(3):869-77.

82. Robertson E, Grace S, Wallington T, Stewart DE. Antenatal risk factors for postpartum depression: a synthesis of recent literature. Gen Hosp Psychiatry. 2004;26(4):289-95

83. Altshuler LL, Hendrick V, Cohen LS. Course of mood and anxiety disorders during pregnancy and the postpartum period. J Clin Psychiatr. 1998.

\section{Publisher's Note}

Springer Nature remains neutral with regard to jurisdictional claims in published maps and institutional affiliations. 